Background and aims V $\delta 2 \mathrm{~T}$ cells have predominantly been investigated in tumour immuno-surveillance and the host defense against viral invasion. The precise role of $\mathrm{V} \delta 2 \mathrm{~T}$ cells in the pathogenesis of SLE remains elusive.

Methods We measured the proportion of peripheral V $\delta 2 \mathrm{~T}$ cells as well as the status and chemokine receptor expression profiles in SLE patients and healthy control (HC). In addition, $\mathrm{V} \delta 2 \mathrm{~T}$ cell infiltration in the kidneys of patients with lupus nephritis was examined.

Results The percentage of peripheral V $\delta 2 \mathrm{~T}$ cells in new-onset SLE was decreased, and negatively correlated with the SLE Disease Activity Index score and the severity of proteinuria. These cells had a decreased apoptosis but an increased proliferation, and they showed increased accumulation in SLE kidneys. Moreover, IL-21 production and CD40L, CCR4, CCR7, CCR8, CXCR1 and CX3CR1 expression in V82 T cells from SLE patients was significantly higher than from HC $(\mathrm{p}<0.05)$, and these factors were down-regulated in association with the repopulation of peripheral V $\delta 2 \mathrm{~T}$ cells in patients who were in remission $(p<0.05)$. In addition, anti-TCR V $\delta 2$ antibodies activation significantly upregulated these chemokine receptors on V82 T cells from $\mathrm{HC}$, and this effect was blocked by inhibitors of PLC- $\gamma 1$, MAPK/Erk, and PI3K signalling pathways.

Conclusions The distribution and function status of $V \delta 2 \mathrm{~T}$ cells from SLE patients are abnormal, and these aberrations may contribute to disease pathogenesis.

\section{DEPLETION OF PLASMACYTOID DENDRITIC CELLS WITH JNJ-56022473 MINIMISES INDUCTION OF AN INTERFERON GENE SIGNATURE IN RESPONSE TO TLR9 AND SLE IMMUNE COMPLEX STIMULATION}

${ }^{1} \mathrm{~K}$ Monaghan* ${ }^{2}$ J Jordan, ${ }^{2} \mathrm{~T}$ Sato, ${ }^{2} \mathrm{M}$ Cesaroni, ${ }^{2}$ J Benson, ${ }^{1} \mathrm{M}$ Ng, ${ }^{1} \mathrm{M}$ Biondo, ${ }^{3} \mathrm{E}$ Morand, ${ }^{3} \mathrm{~A}$ Hoi, ${ }^{1} \mathrm{~N}$ Wilson. ${ }^{1} \mathrm{CSL}$ Limited, Research, Melbourne, Australia; ${ }^{2} J a n s s e n$, Research and Development LLC, Springhouse, USA; ${ }^{3}$ Monash University, Department of Medicine, Melbourne, Australia

\subsection{6/lupus-2017-000215.100}

Background and aims Systemic Lupus Erythematosus (SLE) is associated with an increased IFN gene signature detectable in the peripheral blood. Plasmacytoid dendritic cells (pDC) are potent producers of IFN $\alpha$ in response to TLR9 and TLR7agonists. pDCs which express high levels of CD123 (IL-3R $\alpha$ ) can be depleted by JNJ-56022473 (JNJ-473), a novel Fc-engineered neutralising and depleting therapeutic antibody targeting CD123.

Methods We investigated the effects of pDC depletion with JNJ-473 on IFN $\alpha$ production and gene expression within SLE patient PBMC $(\mathrm{n}=8)$ stimulated with TLR-agonists, SLEimmune complexes (IC, SLE IgG with necrotic cell lysates (NCL)) and sera from SLE patients with NCL.

Results Stimulation with CpGc, SLE-IC or SLE sera was able to induce high levels of IFN $\alpha$, which was greatly decreased by pDC depletion with JNJ-473. SLE-IC and SLE sera stimulation also induced the differential expression of hundreds of genes and could induce similar genes to TLR9-agonism. pDC depletion with JNJ-473 prevented the upregulation of TLR9induced genes. JNJ-473 conferred minimal effects on the induction of genes in response to the TLR4-agonist LPS. Furthermore, a distinct 11-gene IFN signature was induced by CpGc and SLE-IC that was significantly reduced by treatment with JNJ-473, suggesting that the depletion of pDCs with
JNJ-473 could have distinct and specific effects on the detectable IFN signature in many SLE patients.

Conclusions Depletion of pDCs with JNJ-473 is able to dramatically decrease IFN $\alpha$ production and IFN gene signature induced by TLR9-agonists and SLE-IC.

\section{GILZ REPRESENTS A CHECKPOINT LIMITING CYCLICAL EXACERBATION OF INFLAMMATION IN SLE BY TYPE I INTERFERON}

C Nataraja*, S Jones, E Morand. Monash Health, Medicine, VIC, Australia

\subsection{6/lupus-2017-000215.101}

Background and aims Glucocorticoid-induced Leucine Zipper (GILZ) is a GC-inducible gene with multiple immune-regulatory functions, and GILZ deficiency in mice results in the development of a lupus-like phenotype. In Systemic Lupus Erythematosus (SLE), plasmacytoid dendritic cells (pDCs) are major producers of Type 1 interferons (IFN) in response to nucleic acid-containing immune complexes. GILZ inhibits activation of $\mathrm{B}$ cells, $\mathrm{T}$ cells and other myeloid cells and we studied whether GILZ regulates interferon secretion by pDC.

Methods We conducted a study of GILZ expression in human peripheral blood mononuclear cells in-vitro and in-vitro study in GILZ KO mouse model to analyse the regulatory function of GILZ.

Results Our data suggests that loss of GILZ up-regulates type 1 IFN production by pDC in response to TLR7 and TLR9 stimulation. Basal GILZ expression was lower in pDCs than in other myeloid cell types and the relative deficiency of GILZ expression in pDC may predispose these cells to rapid activation and interferon production in SLE. Moreover, GILZ appears to be rapidly downregulated by type 1 interferons and in SLE patients, the level of GILZ, normalised by prednisolone dose, negatively correlated with SLEDAI. Thus, downregulation of GILZ by type I interferon may allow heightened interferon release by $\mathrm{pDC}$, and this mechanism potentially leads to amplification of inflammation and cyclical disease flare-ups in lupus patients.

Conclusions Restoration of GILZ may be a potential therapeutic strategy that could reduce the GC dependence in SLE, a strategy that is appealing since GILZ has thus far not recapitulated any of the metabolic effects of GC.

\section{INHIBITORY EFFECT OF RESVERATROL ON OXIDATIVE STRESS IN MURINE MODEL OF SYSTEMIC LUPUS ERYTHEMATOSUS}

N Pannu* , A Bhatnagar. Panjab University, Biochemistry, Chandigarh, India

\subsection{6/lupus-2017-000215.102}

Background and aims Systemic lupus erythematosus is a systemic autoimmune inflammatory disease where therapeutics are associated with various side effects. As dietary factors have been associated in the prevention of different diseases this study aimed to exploit resveratrol, a polyphenol derived from peanuts, grapes, etc as a dietary factor supporting therapeutics by using its antioxidative properties in the management of oxidative stress in a pristane induced murine model of lupus. Methods The model was established by injecting $0.5 \mathrm{ml}$ of pristane intra-peritoneally and oxidative stress was assessed 
Abstract 102 Table 1 Comparison of enzyme activity of Catalase, Superoxide Dismutase and Glutathione Peroxide in kidney, Liver, lung and spleen at 0 month, after 6 month pristane treatment and after resveratrol treatment. Values are expressed as Mean \pm SEM. Catalase Units: $\mu M$ of $\mathrm{H}_{2} \mathrm{O}_{2}$ decomposed per minute. Superoxide Dismutaes Units: Amount of enzyme which inhibits the rate of reaction by $50 \%$ per minute. Glutathoine Peroxidase: $\mu \mathrm{M}$ of NADPH oxidised per minute.

\begin{tabular}{|c|c|c|c|c|c|}
\hline & & Kidney & Liver & Lung & Spleen \\
\hline \multirow{3}{*}{$\begin{array}{l}\text { Catalase } \\
\text { (Unitsmg } \\
\text { protein) }\end{array}$} & Omonth & $38.61 \pm 4.22$ & $49.36 \pm 2.26$ & $29.38 \pm 3.44$ & $8.2 \pm 0.97$ \\
\hline & $\begin{array}{l}6 \text { month } \\
\text { pristane }\end{array}$ & $31.97 \pm 2.3$ & $47.71 \pm 1.24$ & $14.31 \pm 1.67$ & $6.66 \pm 0.29$ \\
\hline & Resveratrol & $29.56 \pm 3.25$ & $40.63 \pm 3.2$ & $18.81 \pm 3.34$ & $7.06 \pm 0.8$ \\
\hline \multirow{3}{*}{$\begin{array}{l}\text { Superoxide } \\
\text { Dismutase } \\
\text { (Unitsing } \\
\text { protein) }\end{array}$} & 0month & $19.27 \pm 1.64$ & $15.17 \pm 0.8$ & $34.67 \pm 4.07$ & $21.96 \pm 0.74$ \\
\hline & $\begin{array}{l}6 \text { month } \\
\text { pristane }\end{array}$ & $14.24 \pm 0.97$ & $12.32 \pm 0.7$ & $19.68 \pm 1.04$ & $10.33 \pm 1.81$ \\
\hline & Resveratrol & $16.61 \pm 1.48$ & $12.98 \pm 0.19$ & $25.71 \pm 5.1$ & $13.16 \pm 1.19$ \\
\hline \multirow{3}{*}{$\begin{array}{l}\text { Glutathione } \\
\text { Peroxidase } \\
\text { (Unitsing } \\
\text { protein) }\end{array}$} & Omonth & $35.30 \pm 3.29$ & $28.65 \pm 2.24$ & $24.85 \pm 3.95$ & $31.34 \pm 2.62$ \\
\hline & $\begin{array}{l}\text { 6month } \\
\text { pristane }\end{array}$ & $19.7 \pm 3.52$ & $15.84 \pm 2.11$ & $13.56 \pm 2.67$ & $23.99 \pm 2.19$ \\
\hline & Resveratrol & $24.36 \pm 3.75$ & $15.30 \pm 3.36$ & $13.52 \pm 1.86$ & $23.03 \pm 5.9$ \\
\hline
\end{tabular}

after 6 months. $25 \mathrm{mg} / \mathrm{kg}$ body weight of resveratrol was given orally after 2 months of pristane administration daily for the next 4 months.

Results The increased level of reactive oxygen species (Mean Flourescence value at 0 month: $1.70 \pm 0.22$ to $4.89 \pm 1.37$ at 6 months) in peripheral blood mononuclear cells in the model decreased significantly after resveratrol treatment $(1.75 \pm 0.21)$. Pristane treatment decreased the activity of antioxidant enzymes like Catalase in lungs, Superoxide Dismutase in lungs and spleen and Glutathione peroxidase in liver and lungs. Resveratrol increased the activity of all these enzymes and a significant increase was observed in the activity of Superoxide Dismutase in lungs. Pristane treatment decreased the levels of reduced glutathione and increased lipid peroxidation in kidneys, liver, lungs and spleen. Resveratrol treatment restored reduced glutathione level and decreased lipid peroxidation.

Conclusions In conclusion this study states that, the consumption of resveratrol helps in better management of the disease by combating oxidative stress, the root cause of different manifestations observed in lupus.

\section{SMOKING AND PRE-EXISTING ORGAN DAMAGE REDUCE THE EFFICACY OF BELIMUMAB IN SYSTEMIC LUPUS ERYTHEMATOSUS}

${ }^{1}$ I Parodis*, ${ }^{2} \mathrm{C}$ Sjöwall, ${ }^{3} \mathrm{~A}$ Jönsen, ${ }^{1} \mathrm{D}$ Ramsköld, ${ }^{1} \mathrm{~A}$ Zickert, ${ }^{2} \mathrm{M}$ Frodlund, ${ }^{4} \mathrm{~A}$ Sohrabian, ${ }^{5} \mathrm{~L}$ Arnaud, ${ }^{4} \mathrm{~J}$ Rönnelid, ${ }^{1} \mathrm{~V}$ Malmström, ${ }^{3} \mathrm{AA}$ Bengtsson, II Gunnarsson. ' Karolinska Institutet, Department of Medicine- Rheumatology Unit, Stockholm, Sweden; ' Linköping University, Department of Clinical and Experimental Medicine- Rheumatology/AIR, Linköping, Sweden; ${ }^{3}$ Lund University, Department of Clinical Sciences Lund- Rheumatology, Lund, Sweden; ${ }^{4}$ Uppsala University, Department of Immunology- Genetics and Pathology, Uppsala, Sweden; ${ }^{5}$ Hôpitaux Universitaires de Strasbourg, Service de Rhumatologie- Centre National de Référence pour les Maladies Auto-Immunes Systémiques Rares, Strasbourg, France

\subsection{6/lupus-2017-000215.103}

Background and aims Belimumab is the first biologic drug approved for Systemic Lupus Erythematosus (SLE). Here, we aimed to investigate the effects of belimumab on clinical and serologic outcomes, and sought to identify predictors of treatment response in three Swedish real-life settings. 